\title{
Experiences and Attitudes of Registered Nurses towards the Implementation of Quality Improvement Programmes at a Government Hospital in Eswatini
}

\author{
Mfanaleni Jimson Zikalala \\ https://orcid.org/0000-0003-0164-9074 \\ Sefako Makgatho Health Sciences \\ University \\ mzikalal@uniswa.sz
}

\author{
Tinyiko Enneth Nkhwashu \\ https://orcid.org/0000-0003-0315-5393 \\ Sefako Makgatho Health Sciences \\ University \\ tinyiko.nkhwashu@smu.ac.za
}

\author{
Sophy Mogatlogedi Moloko \\ https://orcid.org/0000-0002-2810-4405 \\ Sefako Makgatho Health Sciences \\ University \\ sophy.moloko@smu.ac.za
}

\section{Abstract}

Quality improvement is becoming the cornerstone of effective and efficient delivery of quality healthcare services in recent times. Among other healthcare workers, nurses are the primary implementers of quality improvement programmes (QIPs). Their knowledge, understanding, attitudes and motivation determine the potential effects of the programmes. This study explored the experiences of registered nurses (RNs) towards the implementation of the QIP at a government hospital in Swaziland. The RNs' attitudes toward the programme were also explored. Non-probability, purposive sampling was used to select the sample that comprised of eight RNs. Data were collected through in-depth, face-to-face interviews to explore and describe the RNs' experiences and attitudes regarding the implementation of QIPs. A semi-structured interview guide was used to ask questions until data saturation was reached. Data analysis was conducted following Tesch's method. Ethical considerations were adhered to. The results revealed both negative and positive experiences of the RNs towards QIPs. A negative attitude towards the programme developed due to the manner in which the programmes were introduced to the RNs and their perception of the programme as work overload. However, there was a positive outlook by the RNs towards the programme after they had undergone training on a QIP. The training improved their knowledge, job satisfaction and client outcome. They developed motivation, interest and commitment despite

\section{UNISA $\cong$}




\section{Zikalala, Nkhwashu, Moloko}

the challenges they encountered. The programme also enhanced the spirit of teamwork among the RNs and the support staff.

Keywords: attitudes; experiences; registered nurses (RNs); implementation; quality improvement programme (QIP)

\section{Introduction and Background}

Quality refers to the characteristics or features associated with excellence that form the criteria for evaluating the quality of a specific service (Booyens and Bezuidenhout 2016, 504). According to the World Health Organisation (WHO) $(2016,10)$, the concept of quality is at the core of the regulation of practice in the form of ethical-legal frameworks, standard operation procedures and guidelines. Quality improvement (QI) in the healthcare system is a collective and continuous effort of all stakeholders involved in healthcare to make changes that will lead to better patient outcomes, better performance of the system and better professional development. The stakeholders include the healthcare providers, healthcare managers, patients and their families, researchers and educators (Quality Improvement 2020, 1). Hence, Alishaq and Alajmi $(2017,6)$ view the implementation of QI programmes as a change process that is mainly centred on people.

In 2010, the Swaziland Government (Ministry of Health 2012) initiated the National Quality Management Programme (NQMP) as a basis for its course to formalise quality improvement (QI) endeavours in the country. The aim of this programme was to monitor performance standards for the delivery of healthcare services in the country (University Research Council 2014, 5). Subsequent to this national framework, the Quality Assurance Programme (QAP) was formed in 2012, in order to set strategy and standards for health service delivery. The programme has begun scaling up quality improvement activities to all regions and healthcare facilities of the country (University Research Council 2014, 6). With the assistance of strategic partners, the Ministry of Health in Swaziland has made some progress in implementing some quality improvement programmes (QIPs) at different levels of health institutions in the country (University Research Council 2014, 4). QIPs are structured and purposeful plans that reflect the commitment of the healthcare institution towards improving the quality of service delivery (Booyens and Bezuidenhout 2017, 420). The hospitals in Swaziland adopted a decentralised implementation approach for its QI programmes to monitor, measure and evaluate the quality of services it provides. Each nursing department developed and implemented its QIPs, as per its needs (Booyens and Bezuidenhout 2017, 424).

WHO views the health workforce as one of the six basic blocks that build a quality healthcare system, and nursing personnel is one of the key stakeholders in the formalisation and implementation of QIP initiatives in healthcare (WHO 2016, 10; WHO 2014, 12). The International Council of Nurses (ICN) argues that this role of the nurse in implementing any strategy in a healthcare system is very significant, as the 
more than 16 million nurses practising worldwide, form the backbone of healthcare provision in almost every country (White 2015,6 ).

Nurses, among other healthcare workers, are closely linked to a fundamental responsibility to improve the healthcare system. Therefore, their understanding, motivation and level of involvement determine their potential impact on the QI because they serve as both the recipient and the implementers of programme interventions (Baker et al. 2018, 1). Furthermore, their experiences, knowledge, attitudes, perceptions and values influence how the programme is adopted and administered (Alishaq and Alajmi 2017, 6). In a study conducted in Canada, Gabriel $(2013,1)$ found that some healthcare providers had negative attitudes towards QIPs. The negative attitudes were related to work distress, while nurses' work recognition and satisfaction were positively related to good quality. Swaziland, like other countries, has implemented QIPs (University Research Council 2014, 5). However, the experiences and attitudes of registered nurses (RNs) towards the implementation of the QIPs are not known. Hence, the motivation of the researchers to establish RNs' experiences and attitudes towards the implementation of the QIPs.

\section{Problem Statement}

Swaziland Government's Ministry of Health has implemented the QIPs intending to improve the healthcare service through the monitoring of performance standards for the delivery of healthcare services in the country (University Research Council 2014, 5). Efforts have been made to capacitate RNs about quality improvement in the institution. The first training for 20 healthcare workers from Mbabane Government Hospital was held in 2014. This included other healthcare workers in the Hhohho Region, and these were trained on QI methodologies and approaches (University Research Council 2014, 4). Moreover, the hospital has set the ensuring of adherence to National Quality Assurance Standards (NQAP) as its strategic objective (Mbabane Government Hospital 2011, 16).

However, in the five years of practising as a nurse in the hospital, the researchers have observed that there were challenges in the implementing of QIPs. The researchers believe that nurses play an integral role in implementing QIPs in their respective departments. Therefore, their experiences and attitudes are vital for the successful implementation of the QIPs.

\section{Aim of the Study}

The study aimed at exploring and describing the experiences and attitudes of RNs towards the implementation of QIPs at the selected government hospital in Swaziland. 


\section{Zikalala, Nkhwashu, Moloko}

Research Methodology

\section{Research Design}

A qualitative, exploratory, descriptive and contextual research design was used. The approach and designs enabled the researchers to gain more information regarding the RNs' experiences and attitudes towards the implementation of the QIP at the selected government hospital in Swaziland. The study was conducted within the RNs' practice areas. In-depth, face-to-face, semi-structured interviews and field notes were used to collect data. An audiotape recording device was used as per participant's permission for the researchers to capture and preserve the data as accurately as possible (Creswell 2013, 244).

\section{Study Setting}

The study was conducted in a selected government hospital situated in the Hhohho region of Swaziland. The hospital has 100 medical and paramedical staff, ranging from medical specialists to interns, 258 nursing cadre, ranging from matrons to student nurses, and 233 support staff (Mbabane Government Hospital 2011, 2), with bed occupancy of 500. This hospital was chosen for this research because it is one of the institutions in the country in which extensive QIPs were being rolled out, and because of the institution's strategic placement as the country's national referral hospital and a primary healthcare facility for the surrounding community.

\section{Study Population and Sampling Procedure}

The study population comprised of eight RNs who had been working for at least one year up to 15 years at the selected government hospital. Purposive sampling or judgmental sampling allowed the researchers to consciously pick specific participants who provided rich information on the phenomenon which needed to be studied (Munhall in Grove, Burns, and Gray 2013, 365). Ruane $(2016,216)$ points out that purposive sampling lies with the criteria used as a basis for sampling. The sample size was determined by the saturation of information, which is when data began to repeat itself (De Vos et al. 2011, 36).

\section{Data Collection}

Data collection took place in the RNs' offices. Data collection was conducted using indepth, face-to-face, semi-structured interviews with each participating RN with the aid of an interview guide. All RNs were asked the same central question: "What is your experience towards the quality improvement programmes that are being implemented at the hospital?" The interviews were conducted in the English language as the RNs were conversant with the language. Informed consent was obtained from the participants. An audiotape recording device was used as per participant's permission to capture and preserve the data and notes were taken. The interviews took 30-45 minutes with each participant. 


\section{Zikalala, Nkhwashu, Moloko}

\section{Data Analysis}

Raw audio-recordings and field notes were transcribed verbatim into Microsoft Word files. The data were manually analysed using Tesch's method, following the steps as suggested by Tesch (in Creswell 2013, 247). This method was vital for giving structure to the process, and the data were analysed as described below.

The researchers carefully listened to the audiotaped interviews and read transcripts to understand the whole picture concerning the RNs' views. They then listened to the audiotape and read through the interview notes, writing down ideas that emerged while asking questions like: "What is the importance of the information gathered or what is it about?" The researchers made a list of all topics and then clustered similar topics together. This was followed by the researchers trying to identify major categories, which were written in the margin. The researchers created codes for similar topics, and these were rearranged to see if they become categories. The researchers then found suitable wording for these codes and regrouped them into categories. To indicate relationships, the researchers drew lines connecting related categories. The data were re-coded again to develop more categories and sub-categories.

Trustworthiness was ensured by using Lincoln and Guba's framework, which consists of five criteria namely: credibility, dependability (reliability), confirmability, transferability and authenticity (Lincoln and Guba 1985 in Anney 2014, 275; Polit and Beck 2017, 497). To ensure credibility, the researchers allowed each participant to verbally confirm that the transcription of her/his interview is a reflection of what has been said. A trust relationship was built with the participants to familiarise them with the environment. Transferability was ensured by the researchers by giving a brief description of the data collection method used. The researchers depended on field notes and an audiotape when transcribing data to ensure that no information was missed. To ensure confirmability, the researchers made sure that preconceived ideas and bias did not influence the results. Authenticity refers to the extent to which researchers, fairly and faithfully, show a range of realities (Lincoln and Guba 1985, 300; Polit and Beck 2012, 493).

\section{Ethical Consideration}

The study was approved by the ethics committee of the Sefako Makgatho Health Sciences University (SMUREC/H/119/2018:PG). Permission to conduct the research was obtained from the different health authorities: Ministry of Health's Swaziland National Health Research Review Board (NHRRB) to ensure ethical compliance of the research and for approval, as well as from the selected government hospital. For research to be considered ethical, the rights of the participants are of paramount importance. According to Grove et al. $(2013,162)$, the ethical research principles were formulated to protect the human rights of the participants, namely: the right to selfdetermination, right to privacy, right to anonymity and confidentiality, right to fair treatment and right to protection from discomfort and harm. Informed consent was obtained from each participant before undertaking the research, so that all were well 


\section{Zikalala, Nkhwashu, Moloko}

informed about the benefits and risks of the research. They were made aware that they were free to withdraw from an interview at any time without penalty.

\section{Research Findings}

Eight RNs, of whom three were females and five were males, participated in the study. Their ages ranged between 24 and 42 years. Four of the participants had work experience of one year to five years. The other four had more than five years of work experience, with the highest being 10 years. All but one participant had some experience, either currently serving or had previously served, or as a departmental representative to the hospital's quality management team. 


\section{Zikalala, Nkhwashu, Moloko}

Table 1: Demographic profile of participants

\begin{tabular}{|c|c|c|c|c|c|}
\hline Participant & Sex & $\begin{array}{l}\text { Age } \\
\text { (yrs) }\end{array}$ & $\begin{array}{l}\text { Work } \\
\text { experience } \\
\text { in hospital }\end{array}$ & Qualifications & $\begin{array}{l}\text { Experience in } \\
\text { relation to QIPs }\end{array}$ \\
\hline 001 & $\bar{F}$ & 38 & $10 \mathrm{yrs}$ & $\begin{array}{l}\text { Bachelor of Nursing } \\
\text { Sciences: Advanced } \\
\text { Medical-Surgical Nursing } \\
\text { and Midwifery }\end{array}$ & $\begin{array}{l}\text { Current } \\
\text { departmental nurse } \\
\text { focal person for } \\
\text { quality }\end{array}$ \\
\hline 002 & $\mathrm{~F}$ & 40 & $8 y r s$ & $\begin{array}{l}\text { Bachelor of Nursing in } \\
\text { Health Services } \\
\text { Management, Education } \\
\text { and Community Health, } \\
\text { Diploma in General } \\
\text { Nursing, Post Graduate } \\
\text { Diploma in Midwifery }\end{array}$ & $\begin{array}{l}\text { Current } \\
\text { departmental nurse } \\
\text { focal person for } \\
\text { quality, } 2 \text { years }\end{array}$ \\
\hline 003 & $\mathrm{M}$ & 33 & $9 y r s$ & $\begin{array}{l}\text { Diploma in General } \\
\text { Nursing }\end{array}$ & $\begin{array}{l}\text { Newly appointed } \\
\text { departmental nurse } \\
\text { focal person for } \\
\text { quality, } 4 \text { months }\end{array}$ \\
\hline 004 & M & 42 & $8 y r s$ & $\begin{array}{l}\text { Diploma in General } \\
\text { Nursing } \\
\text { Post Graduate Diploma in } \\
\text { Mental Health } \\
\text { Health Sciences }\end{array}$ & $\begin{array}{l}\text { Currently } \\
\text { departmental nurse } \\
\text { focal person for } \\
\text { quality, } 4 \text { months }\end{array}$ \\
\hline 005 & $\mathrm{M}$ & 24 & $5 y r s$ & $\begin{array}{l}\text { Diploma in General } \\
\text { Nursing }\end{array}$ & $\begin{array}{l}\text { Former } \\
\text { departmental nurse } \\
\text { focal person for } \\
\text { quality, } 2016 \\
\end{array}$ \\
\hline 006 & $\mathrm{~F}$ & 26 & $3 y r s$ & $\begin{array}{l}\text { Bachelor of Nursing } \\
\text { Sciences: Community } \\
\text { Health and Psychiatric } \\
\text { Nursing } \\
\text { Diploma in General } \\
\text { Nursing }\end{array}$ & $\begin{array}{l}\text { Current } \\
\text { departmental nurse } \\
\text { focal person for } \\
\text { quality, for the past } \\
3 \text { years }\end{array}$ \\
\hline 007 & $\mathrm{M}$ & 29 & $2 \mathrm{yrs}$ & $\begin{array}{l}\text { Bachelor of Nursing } \\
\text { Sciences: Community } \\
\text { Health and Midwifery }\end{array}$ & None \\
\hline 008 & $\mathrm{M}$ & 31 & $4 y r s$ & $\begin{array}{l}\text { Bachelor of Nursing } \\
\text { Sciences: Community } \\
\text { Health and Midwifery }\end{array}$ & $\begin{array}{l}\text { Departmental } \\
\text { representative to } \\
\text { the hospital's } \\
\text { Quality } \\
\text { Management Team }\end{array}$ \\
\hline
\end{tabular}

Two themes emerged from the data analysis as shown in table 2. The registered nurses (RNs) had diverse experiences of the QIPs and they portrayed a change in attitude towards the implementation of the QIPs. 
Table 2: Registered nurses' experiences and attitudes towards the implementation of the quality improvement programme

\begin{tabular}{|l|l|}
\hline Themes & Categories \\
\hline $\begin{array}{l}\text { Diverse experiences of the } \\
\text { quality improvement programme }\end{array}$ & $\begin{array}{l}\text { Negative experiences of the quality improvement } \\
\text { programme }\end{array}$ \\
\cline { 2 - 2 } & $\begin{array}{l}\text { Positive experiences of the quality improvement } \\
\text { programme }\end{array}$ \\
\hline $\begin{array}{l}\text { Change in attitude towards the } \\
\text { implementation of the quality } \\
\text { improvement programme }\end{array}$ & $\begin{array}{l}\text { Initial negative attitudes towards the implementation of } \\
\text { the quality improvement programme }\end{array}$ \\
\cline { 2 - 2 } & $\begin{array}{l}\text { Positive attitudes towards the implementation of the } \\
\text { quality improvement programme }\end{array}$ \\
\hline
\end{tabular}

\section{Theme 1: Diverse experiences of the quality improvement programme}

Registered nurses (RNs) had both negative and positive experiences about the implementation of QIPs. The negative experiences were due to a lack of respect from the quality improvement officer and the feelings of helplessness and hopelessness regarding the effective and efficient implementation of the QIPs. The positive experiences were due to improved knowledge, improved job satisfaction and good client outcome.

RNs expressed experiencing some disrespect, rudeness and some form of dictatorship from the nurse quality improvement officer. The disrespect and rudeness created unsavoury experiences for the RNs regarding the QIPs. In turn, RNs developed negativity towards the programmes, which was tantamount to failure of the implementation of the programmes in the hospital:

P001: The QIP was perceived as this exercise that is personified as this person who will come and shout at you even in front of patients, and you would feel really bad. You would feel disrespected, like quality was like a rude thing for Mbabane Government.

The participants in this study commented that they felt like much still needed to be done in the hospital to at least see some form of progress towards the implementation of QIPs. They felt like everything going on in the hospital was not right, and the programmes were not possible or workable in the hospital. The results showed that organisational challenges were passed on to the RNs, even though it was clear that these challenges were beyond their scope of intervention. As a result, they developed feelings of helplessness and hopelessness regarding the effective and efficient implementation of the QIPs:

P001: You can see that it is a good thing, but the frustrating part is it is not workable at Government Hospital.

P005: If we go back to looking into the foundation and the background, we definitely lack a lot. You know quality is quite difficult to implement, that is what I can say, at a 


\section{Zikalala, Nkhwashu, Moloko}

setting where everything is just so poorly. I do not know; maybe we are just helpless people.

P006: It is impossible, according to me. We are just playing around wasting resources because there is a lot that is wrong. In fact, everything is wrong.

Some RNs expressed motivation to work because of the improved knowledge and understanding of the QIPs. They felt enlightened and developed insight into the QIPs.

P001: I think basically ... now there is a mild understanding of it [QIPs], we are appreciating the knowledge, which we are saying yes, we know what we are supposed to do. People are becoming more enlightened.

P008: So now we have got the motivation to work with the people. Now we have got the information; now we want to work.

RNs reported that the QIPs improved job satisfaction and working relations with their colleagues. They experienced good working relations with colleagues, which transformed the way they viewed and experienced their jobs. They further expressed their happiness by verbalising how they value their work because they have direction or know what to do, and their clients are happy with the service.

P002: Personally, I think I have learnt to value my work more. It enhances job satisfaction because you know it is the high quality you can ever give to your patient. My patients are happy. If they are happy, I am also happy. Even amongst ourselves as workers, there are good working relationships. We are doing something that is standardised. So, you are always happy.

P003: And if followed to the latter end it will see us progressing and our clientele happy. I have not experienced problems with my fellow colleagues.

\section{Theme 2: A change in attitude towards the implementation of the quality improvement programme}

The experiences that RNs had about the implementation of the QIPs influenced their attitudes towards the QIPs negatively and positively. At the inception stage, the RNs had negative attitudes towards the implementation of the QIPs. However, at a later stage, their attitude changed and they were willing to exert the added effort to ensure the success of the QIPs. The negative attitude was mainly because of how the QIPs were introduced to them; it was viewed by some RNs as unprofessional and outright rude. The negativity around the QIPs by the RNs was not towards the programme per se, but it was towards the nurse quality officer whose inter-personal relations with the RNs were not good. The behaviour resulted in the RNs harbouring hatred and negative attitudes towards the programmes, based on how the QIPs were introduced.

P001: ... but the manner of approach as it was introduced was not good to the point that nurses at Mbabane Government hated quality. Initially, there was a bad attitude towards 


\section{Zikalala, Nkhwashu, Moloko}

quality. But as ... I would say it was not towards quality. It was towards the officer, not towards the programme.

The nurses found it very difficult to accept the QIPs. They perceived QIPs as an isolated programme, not as part of their daily work, but as a work overload that is impossible to implement due to lack of resources.

P004: You will be working hard doing rounds from morning up until lunchtime. Then, when the sister comes with the idea of the quality you are just like, you cannot even appreciate what we are doing, you are busy nagging, nagging. We never accepted it well. It is seen as work overload more than anything else.

P006: The implementation of the QIPs is impossible according to me, we are just playing around wasting time and resources because there are many wrong things. In fact, everything is wrong; we do not have staff and resources.

Despite the initial negativity towards the QIPs, RNs eventually showed a positive attitude towards the QIPs, even though they were not satisfied with the current work conditions in the hospital. They were more receptive of the programme and committed to its activities, especially after the training. The positive attitudes towards the programmes (like showing interest in the programmes and committing to improving quality), were shown to have improved since inception. Furthermore, the current knowledge of the programme and appreciation towards it, override the past negativity.

P001: QIPs are a good thing. We know what we are supposed to do now. Even though we have to make adjustments there and there. We gradually appreciate quality.

P003: I personally think they [QIPs] mean well. The programme means well. It affected me positively. I am expected to be as proficient as I can in performing my duties in terms of improving the quality by virtue of being the focal person.

P008: When the programme was introduced people were given five days' training on the Quality Management systems. That has brought clarity as to how it fits into our work. So now people saw what role they are supposed to play in the quality assurance issues.

RNs realised the value of having QIPs in the hospital. There seems to have been a shift towards acknowledging the important role that QIPs play in the entire service delivery system of the hospital, as well as operational levels, as they improve patient care. This is supported by the quotes below:

P002 Personally I think I have learnt to value my work more because it helps us to improve patient care and also to improve our knowledge and skills. It improves our competency if it is done properly.

P006: I felt it was a good initiative because it is going to help the hospital to run better to improve patient care and all that. 


\section{Zikalala, Nkhwashu, Moloko}

P007: So as for me, I am really happy for such programmes. It is a very important programme. We need more programmes like this one.

The results also showed that not only RNs, but even other cadres like support staff acknowledged their responsibility towards the QIPs. In some departments it was reported that after capacity building in QIPs, most of the staff were encouraged by their newly acquired knowledge and they felt more responsible and interested in the development and implementation of many tools in the hospital. The implementation of QIPs has instilled some sense of responsibility among the staff, as observed by RNs below:

P001: Now you find that we can correct each other without having to involve someone from outside. Everyone is being responsible gradually, but it is not yet up to the required standard. Yes. But it is [the RNs' attitude towards QIPs] improving.

P008: Ehh, we have also seen people actively participating in the formulation of various documents, like the strategic plan for the hospital that is currently being formulated.

\section{Discussion}

The results showed some diverse attitudes by the RNs towards the implementation of the quality programmes. The RNs expressed their initial negative attitudes towards the implementation of the QIP, especially during its inception stages because of the manner in which it was introduced to them, which could be viewed by some RNs as unprofessional and outright rude. The negativity was not towards the programme but towards the nurse quality officer whose inter-personal relations with the RNs were not good. The nurse quality officer did not create the right climate for implementing quality, and thereby ruined interpersonal relations. The manner in which QIP efforts are introduced and managed affect healthcare providers' attitudes and engagements towards the programme (Gadolin and Andersson 2017, 416). Booyens and Bezuidenhout (2017, 426) allude that creating the right climate for implementing quality is very important, especially during the development phase. Hence, a constructive relationship among managers and employees is considered a prerequisite for employees to be actively involved in quality improvement activities (Gadolin and Andersson 2017, 417). Poor interpersonal relationships between health professionals or groups are considered detrimental to the achievement and sharing of common goals such as quality improvement, and quality assurance in healthcare settings depends on interpersonal relationships that enable effective communication and understanding between individuals (Amukugo, Nangombe, and Karera 2020).

Furthermore, it appears from the results of this study that RNs experienced the QIPs as a burden to them. They found it challenging to change from their old way of doing things; hence they perceived the QIPs as impossible to implement. This could be mainly due to a lack of knowledge during the initiation phase, which indicated the need for building capacity for successful implementation of the QIPs. Singh, Wiese, and Sillerud $(2019,8)$ attest that implementing new initiatives often lead to frustrations, anxiety and 


\section{Zikalala, Nkhwashu, Moloko}

resistance, unless the benefits of these initiatives are straightforward and can be easily seen. In addition to a lack of knowledge, motivation towards the implementation of the QIPs was low due to a shortage of resources, especially nurses. This caused a severe hindrance to the implementation of quality initiatives for better care, which in turn reflected poorly on the quality-oriented healthcare system (Nyhus and Kamarah 2017, 17).

However, as the programme was implemented, nurses had positive experiences of the QIPs because of the knowledge acquired during the process; consequently, positively changing their attitudes. The results of this study are consistent with the findings of Khumalo $(2018,19)$, who found a significant and positive relationship between attitudes toward the implementation of quality improvement with the practise of knowledge. The working experience was found to increase knowledge and contributed to working more efficiently (Robertsson and Yochin 2017, 17). Similarly, Sjølie, Hartviksen, and Bondas $(2020,7)$ found that the implementation of quality improvement methods and techniques gave nurse leaders the knowledge and a sense of proficiency in patient care. They developed responsibility for patient safety and improved healthcare service

The training was also found to have a significant role in improving attitudes and motivation towards the implementation of the QIPs. Post the training, the RNs acknowledged the importance of being proficient in their work and developed a desire to work hard towards the implementation of QIPs. They felt empowered and motivated to create a more enjoyable working atmosphere. They recognised the importance of QIPs in improving the quality of patients' care. Similarly, in a study assessing the attitudes of healthcare professionals towards quality improvement in Sweden, Siverbo, Eriksson, and Raharjo $(2014,6)$ observed unpleasant attitudes of healthcare workers towards the QIPs; however, the attitude changed after six months in response to a training programme on quality improvement (Siverbo et al. 2014, 211). Training of staff members on QIPs is considered very important and is necessary for strengthening their knowledge and positive attitudes towards QIPs (Booyens and Bezuidenhout 2017, 426; Mahomed and Asmall 2017). Hill et al. (2020,2) attest that better-informed healthcare workers deliver quality healthcare services to clients.

The positive experiences and attitudes towards the implementation of the QIPs after the training did not only improve the knowledge and commitment, but also improved interrelationships among the staff. The involvement of other cadres, like support staff, appeared to have improved the teamwork and enhanced a sense of responsibility and interest towards the QIPs. Enthusiasm and teamwork by all stakeholders were found to contribute positively towards achieving quality improvement goals (Limato et al. 2019, 7). Although the active involvement of nurse managers in QIPs was not discussed in this study, their participation is required as the planners and the organisers of the programme. They should be hands-on in order to give direction to the forefront implementers (Kassim et al. 2015). 


\section{Zikalala, Nkhwashu, Moloko}

\section{Limitations of the Study}

The researchers identified the following restrictions that may affect the credibility and generalisability of the findings of this study:

- There is limited literature available on the experiences and attitudes of RNs towards quality, especially in the region.

- Rich information that could have given more insight, especially on the initial phases of the programmes in the selected hospital, was lost to RNs who were promoted to nurse manager positions and were not participants of this study.

- The study was limited to one hospital and generalising its findings to the whole country might not be possible, as different results may be obtained from other hospitals.

\section{Recommendations}

Based on the findings regarding the experiences and attitudes that RNs had towards the implementation of QIPs at the selected government hospital, the study has identified a strong relationship that exists between experiences and attitudes due to poor interpersonal relationships and lack of training, and also among the healthcare workers towards the implementation of QIPs with the practise of knowledge and sharing. It is, therefore, recommended that more time should be allocated to educate managers and quality improvement officers on how to create a positive and enabling environment for implementing the QIPs. Orientation and training should be done for RNs, including other categories before the actual implementation of QIPs. The inputs of all stakeholders, including the RNs, should be sought before the implementation of the programme so that everyone could assume ownership of the programme. This will prevent staff resistance and will enhance interest and motivation toward the programmes, consequently, increasing the effectivity of the programme towards improving service delivery and quality nursing care. Further research is needed on the evaluation of structural and managerial processes that influence quality-related issues in the hospital or nationally.

\section{Conclusion}

Experiences and attitudes of the RNs towards the implementation of the QIPs in the hospital were drawn mainly from their experiences that they encountered during service delivery. These attitudes were seen to have evolved from negative to generally positive, owing to factors like improved knowledge due to the experience and training. The results showed that multiple aspects make it difficult for nurses to proceed with quality improvement. The results also showed that the nurses had positive experiences, even though there were issues. The effort of conducting training on the QIPs was to encourage commitment and to enhance the implementation process of the QIPs. The RNs experienced that training and commitment rested in the improvements that a quality implementation programme may bring about in general practice. The study 


\section{Zikalala, Nkhwashu, Moloko}

provided insight into RNs' approach to QIP implementation, and told of an array of cognitive, motivational and practical obstacles embedded in the implementation relationships of RNs.

The main conclusion from the findings is that RNs' understanding and appreciation of the importance of having the programmes override the obstacles that could obscure their positive attitude towards the programmes. The former need to be reinforced, whilst the latter need to be addressed for effective implementation of the QIPs in the selected hospital. Lastly, this study supports the fact that attitude influences the implementation of QIPs in the development of knowledge-sharing practices among healthcare workers. Good collaboration between colleagues and feeling acknowledged and listened to made the nurses feel satisfied. Improvements in the quality of care directly influence the outcome of patient care.

\section{Acknowledgements}

The authors would like to acknowledge Sefako Makgatho Health Sciences University for the research grant which enabled them to conduct this research study, the Ministry of Health's Swaziland National Health Research Review Board (NHRRB) for approval, as well as permission from the selected government hospital to use health facilities, and participants, who allowed their thoughts to be explored through their participation in the project.

\section{References}

Alishaq, M., and J. Alajmi. 2017. Improvement Science Made Simple. Doha: Hamad Healthcare Quality Institute.

Amukugo, H. J., J. P. Nangombe, and A. Karera. 2020. "Experiences of Inadequate Interpersonal Relationships Regarding Quality Improvement and Quality Assurance in the Ministry of Health and Social Services in Namibia." https://doi.org/10.1080/21665095.2020.1779598.

Anney, V. N. 2014. Ensuring the Quality of the Findings of Qualitative Research: Looking at Trustworthiness Criteria. Dar-es-Salaam: University of Dar Es salaam.

Baker, U., A. Petro, T. Marchant, S. Peterson, F. Manzi, A. Bergstrom and H. Hanson. 2018. “Health Workers' Experiences of Collaborative Quality Improvement for Maternal and Newborn Care in Rural Tanzanian Health Facilities: A Process Evaluation Using the Integrated 'Promoting Action on Research Implementation in Health Services' Framework." PLoS ONE 13 (12): e0209092. https://doi.org/10.1371/journal.pone.0209092.

Booyens, S. W., and M. Bezuidenhout. 2016. Dimensions of Healthcare Management, 3rd edition. Cape Town: Juta. 


\section{Zikalala, Nkhwashu, Moloko}

Booyens, S. W., and M. Bezuidenhout. 2017. Dimensions of Healthcare Management, 3rd edition. Cape Town: Juta.

Creswell, J. 2013. Research Design: Qualitative, Quantitative, and Mixed Methods Approaches, 4th edition. California: Sage.

De Vos, A. S., C. S. L. Delport, C. B. Fouche, and H. Strydom. 2011. Research at Grass Roots: For the Social Sciences and Human Service Professionals. ISBN: 9780627027727. 4th edition.

Gabriel, A. 2013. Quality Healthcare from the Nurses'Perspective. Saskatoon: University of Saskatchewan.

Gadolin, C., and T. Andersson. 2017. "Healthcare Quality Improvement Work: A Professional Employee Perspective.” International Journal of Healthcare Quality Assurance 30 (5). https://doi.org/10.1108/IJHCQA-02-2016-0013.

Grove, S. K., N. Burns, and J. R. Gray. 2013. The Practice of Nursing Research: Appraisal, Synthesis, and Generation of Evidence, 7th edition. St. Louis, MO: Elsevier Saunders.

Hill, J. E., A. Stephani, P. Sapple, and A. J. Clegg. 2020. "The Effectiveness of Continuous Quality Improvement for Developing Professional Practice and Improving Healthcare Outcomes: A Systematic Review.” Implementation Science 15 (23). https://implementationscience.biomedcentral.com/articles/. https://doi.org/10.1186/s13012020-0975-2.

Kassim, L., A. Raman, Y. Don, Y. Daud, and M. S. Omar. 2015. "The Association between Attitude towards the Implementation of Staff Development Training and the Practice of Knowledge Sharing Among Lecturers." School of Education and Modern Languages, University Utara Malaysia, Sintok, Kedah, Malaysia. International Education Studies 8 (12). Published by the Canadian Center of Science and Education. https://doi.org/10.5539/ies.v8n12p108.

Khumalo, B. 2018. "Ending Tuberculosis and AIDS: A Joint Response in the Era of Sustainable Development Goals Country Submissions." Cabrini Ministries. Geneva: UNAIDS Programme Coordinating Board. https://www.unaids.org/sites/default/files/media_asset/20180625_UNAIDS_PCB42_CRP3 _Thematic_TBHIV-Country-Submissions_EN.pdf.

Limato, R., P. Tumbelaka, R. Ahmed, and S. Nasir. 2019. "What Factors Do Make Quality Improvement Work in Primary Healthcare? Experiences of Maternal Health Quality Improvement Teams in three Puskesmas in Indonesia." Liverpool School of Tropical Medicine. Plos One 14 (12). https://doi.org/10.1371/journal.pone.0226804.

Lincoln, Y. S., and E. G. Guba. 1985. Naturalistic Inquiry. Newbury Park: Sage. https://doi.org/10.1016/0147-1767(85)90062-8. 


\section{Zikalala, Nkhwashu, Moloko}

Mahomed, O. H., and S. Asmall. 2017. "Professional Nurses' Perceptions and Experiences with the Implementation of an Integrated Chronic Care Model at Primary Healthcare Clinics in South Africa." Curationis 40 (1): a1708. AOSIS. https://doi.org/10.4102/curationis.v40ii.i708.

Mbabane Government Hospital. 2011. "Mbabane Government Hospital Strategic Plan 20112015.” Mbabane: Swaziland Government.

Ministry of Health. 2012. "National Quality Management Programme (NQMP).” Mbabane: Swaziland Government.

Nyhus, H. B., and M. M. Kamarah. 2017. "Quality Improvement in Emergency Service Delivery: Assessment of Knowledge and Skills Amongst Emergency Nurses at Connaught Hospital, Sierra Leone.” African Journal of Emergency Medicine 7 (7): 113-117. https://doi.org/10.1016/j.afjem.2017.04.002.

Polit, D. F., and C. T. Beck. 2012. Nursing Research: Generating and Assessing Evidence for Nursing Practice, 9th edition. United States of America: Lippincott Williams and Wilkins.

Polit, D. F., and C. T. Beck. 2017. Nursing Research: Generating and Assessing Evidence for Nursing Practice, 7th edition. Philadelphia: Lippincott William and Wilkins.

Quality Improvement and Healthcare: The Mayo Clinic Quality Academy Experience. 2020. J Clin Tuberc Other Mycobact Dis. https://doi.org/10.1016/j.jctube.2020.100170.

Robertsson, A., and E. Yochim.2017. Nurses' Experiences of Working with Quality Improvement in Tanzanian Healthcare. Arusha.

Ruane, J. 2016. Introducing Social Research Methods: Essentials for Getting the Edge. Oxford: John Wiley and Sons.

Singh, J., A. Wiese, and B. Sillerud. 2019. "Using Phenomenological Hermeneutics to Understand the Experiences of Managers Working with Quality Improvement Strategies in an Assisted Living Facility." Healthcare 7 (87). https://www.ncbi.nlm.nih.gov/pmc/articles/PMC6787700/. https://doi.org/10.3390/healthcare7030087.

Siverbo, K., H. Eriksson, and H. Raharjo. 2014. “Attitudes toward Quality Improvement among Healthcare Professionals: Lessons from a Hospital-wide Quality Initiative.” International Journal of Quality and Service Sciences 6 (2): 203-212. http://publications.lib.chalmers.se/records/fulltext/202485/local_202485.pdf. https://doi.org/10.1108/IJQSS-02-2014-0017.

Sjølie, B. M., A. Hartviksen, and T. Bondas. 2020. "Navigation to Prioritising the Patient: First-line Nurse Managers' Experiences of Participating in a Quality Improvement Collaborative." Health Services Research. https://doi.org/10.1186/s12913-020-4918-z. 


\section{Zikalala, Nkhwashu, Moloko}

University Research Council. 2014. "United States Agency for International Development (USAID) Applying Science to Strengthen and Improve Systems (ASSIST) Project Swaziland Country Report FY14. Bethesda: USAID ASSIST Project." https://www.usaidassist.org/sites/default/files/assist_fy14_annual_performance_monitorin g_report_15nov2014_rev_ada.pdf.

White, J. 2015. "ICN Policy Brief: World Health Organisation Global Strategy on Human Resources for Health in the era of the post 2015 Sustainable Development Goals: Nursing's Essential Contribution. Jean-Marteau: International Council for Nurses (ICN)." http://www.who.int/workforcealliance/knowledge/resources/ICN_PolicyBriefforNNAsNur singHRandSDGs.pdf?ua=1.

World Health Organisation (WHO). 2014. Regional Office for Africa. "WHO Country Cooperation Strategy 2014-2019 Swaziland.” Brazzaville: WHO.

World Health Organisation (WHO). 2016. "Global Strategy on Human Resources for Health Workforce 2030”. New York: WHO. 